\title{
Ulcer associated cell lineage glands expressing trefoil peptide genes are induced by chronic ulceration in ileal pouch mucosa
}

\author{
M Pera, J Heppell, R Poulsom, F V Teixeira, J Williams
}

\begin{abstract}
Background-Chronic ulcerative conditions in the gastrointestinal tract result in the appearance of the ulcer associated cell lineage (UACL). The glands of this new cell lineage secrete epidermal growth factor, transforming growth factor $\alpha$, and the trefoil factor family (TFF) peptides, which are known to participate in repair processes. Pouchitis is the most frequent complication of ileal pouch-anal anastomosis. Aim-Our aim was to determine whether the mucosal ulceration present in pouchitis can induce the development of UACL glands.
\end{abstract}

Methods-Biopsies from ileal pouches with pouchitis $(n=10)$, healthy pouches $(n=5)$, and normal terminal ileum $(n=5)$ were studied. Expression of TFF mRNA was assessed by in situ hybridisation. TFF1 and TFF2 proteins were localised by immunochemistry.

Results-UACL glands containing TFF1 and TFF2 were observed in six patients with pouchitis. In some glands, there was TFF3 mRNA as has been reported for Crohn's UACL. None of the biopsies from ileal reservoirs without pouchitis showed UACL glands $(p<0.05)$. Neither TFF1 nor TFF2 expression was detected in ileal reservoirs without pouchitis.

Conclusion-UACL glands arise de novo in ileal pouch mucosa of patients with pouchitis and express all three TFF peptide genes. Chronic inflammation alone, present in healthy pouches, is not enough to stimulate the growth of the UACL, and additional stimuli consequent on ulceration may be needed.

(Gut 2001;48:792-796)

Keywords: ulcer associated cell lineage; trefoil peptides; chronic ulceration; pouchitis

Presented at the 7 th United European Gastroenterology Week, November 17, 1999, Rome, Italy, and published in part in an abstract in Gut 1999:45 (Suppl V);A334

Correspondence to: Dr M Pera, Department of Surgery, Hospital Clinic,

University of Barcelona,

Villarroel 170, 08036

Barcelona, Spain.

28370mpr@comb.es

Accepted for publication 5 December 2000 new luminal environment acquiring the glandular morphology of the large bowel. The villi atrophy, the crypts elongate, and the goblet cells become larger. ${ }^{2}$ It has also been demonstrated that the mucus produced changes from the small bowel type sialomucin to a sulphated sialomucin more typical of colon. ${ }^{3}$ In addition, chronic inflammation has been described and the grade of mononuclear, plasma cells, and eosinophilic infiltration increases. ${ }^{4}$ Based on the severity and fluctuation of histological inflammation, patients can be divided into three groups: (1) chronic changes are minor and acute inflammation is never seen, (2) chronic changes are more severe and there are transient episodes of acute inflammation, and (3) severe chronic and severe acute inflammation are constantly present. Differentiation of the three groups is usually well established within six months after restoration of the faecal stream. $^{5}$

Pouchitis is the commonest long term complication affecting pouches. Clinical symptoms include diarrhoea, sometimes with blood, fever, abdominal cramps, malaise, anorexia, and occasionally extraintestinal manifestations. ${ }^{6}$ Endoscopic examination of the pouch shows the mucosa to be oedematous, hyperaemic, and friable, similar to its presentation in acute ulcerative colitis. ${ }^{7}$ The prevalence of pouchitis in most large series is $15-35 \%$ and the rates vary with duration of follow up and diagnostic criteria. ${ }^{8}$ At the Mayo Clinic, $32 \%$ of patients developed at least one episode of pouchitis over a mean period of eight years. Of these patients, $61 \%$ had at least one recurrent episode and $7 \%$ had chronic unremitting pouchitis. ${ }^{7}$ When symptoms of pouchitis appear, a variable degree of acute mucosal inflammation accompanies the chronic inflammatory changes with polymorphonuclear neutrophil infiltration, goblet cell depletion, crypt abscesses, and mucosal ulceration. ${ }^{9}$

Chronic inflammation and ulceration in the gastrointestinal tract is associated with the development of a new cell lineage from mucosal stem cells. ${ }^{10}$ The "ulcer associated cell lineage" (UACL) was originally described as "pyloric metaplasia" occurring in the ulcerated mucosa of the ileum in cases of chronic regional ileitis. ${ }^{11}$ It has since been reported in other chronic inflammatory conditions such as reflux oesophagitis in association with Barrett's oesophagus, ${ }^{12}$ peptic ulcer, and chronic cholecystitis. ${ }^{13}$ However, the phenotype of these cells has only been investigated in recent years, revealing that this cell lineage is different from other gut lineages, and it cannot be regarded as a metaplasia. ${ }^{14}$ The UACL synthesises and
Abbreviations used in this paper: EGF, epidermal growth factor; IPAA, ileal pouch-anal canal anastomosis; PDAI, pouchitis disease activity index; TGF- $\alpha$, transforming growth factor $\alpha$; TFF, trefoil factor family; UACL, ulcer associated cell lineage. 
secretes epidermal growth factor (EGF), transforming growth factor $\alpha$ (TGF- $\alpha$ ), and all three peptides of the human trefoil factor family $(\mathrm{TFF})^{15}$ : TFF1 (known previously as $\mathrm{pS} 2$ ), TFF2 (spasmolytic polypeptide), and TFF3 (intestinal trefoil factor). These peptides are normally expressed in specific regions of the gastrointestinal tract and are involved in the maintenance of mucosal integrity. ${ }^{16}{ }^{17}$ As the UACL appears only where there is enteric ulceration and secretes proteins promoting mucosal healing, it has been suggested that it has a reparative function within the gut. ${ }^{10}$

The aim of this study was to determine whether the inflammatory changes and ulceration present in pouchitis can induce the development of UACL glands that produce TFF peptides locally to promote epithelial restitution and repair.

\section{Material and methods}

PATIENTS AND HISTOLOGICAL MATERIAL All patients with chronic or recurrent pouchitis (more than two episodes) attending our colorectal unit for the past five years were included in the study. Disease duration in all cases was at least six months. Blocks of paraffin embedded biopsies from patients $(n=10)$ were reviewed. Biopsies from patients with an IPAA without pouchitis $(n=5)$ and from normal terminal ileum ( $\mathrm{n}=5)$ were also studied. Material was retrieved from the archives of the Department of Pathology, Mayo Clinic Scottsdale. All tissues had been fixed in neutral buffered formalin and embedded in paraffin wax in the conventional manner. Serial sections were cut at $4 \mu \mathrm{m}$ and stained with haematoxylin and eosin, diastase periodic acid-Schiff/alcian blue, or used for immunohistochemical and in situ hybridisation procedures. The criteria used in the identification of the UACL glands were morphology and mucin secretion and presence and pattern of distribution of the three TFF peptides. Access to all histological material satisfied the requirements of the Mayo Clinic Scottsdale Research Committee.

POUCHITIS DISEASE ACTIVITY INDEX (PDAI)

A pouchitis score was calculated to confirm the diagnosis of pouchitis. Because the use of histological criteria alone has been found to be inaccurate in nearly $50 \%$ of patients, ${ }^{18}$ we selected the PDAI described by Sandborn and colleagues ${ }^{19}$ based on symptoms, endoscopic findings, and histological evaluation that seems to be a better tool in distinguishing between patients with or without pouch inflammation. According to this index, pouchitis is defined as a total score $>7$. All patients with pouchitis included in this study had a PDAI $>9$.

\section{IMMUNOHISTOCHEMISTRY}

Monoclonal antibodies to detect TFF1 and TFF2 were used as described previously, ${ }^{20}$ using an avidin-biotin complex method that produced a brown stain from 3, 3' diaminobenzidine and hydrogen peroxide. No antiserum capable of localising TFF3 specifically was available. Control sections of stomach and small intestine containing UACL glands stained appropriately (not shown).

IN SITU HYBRIDISATION

Sites of expression of TFF mRNAs were assessed using in situ hybridisation to antisense riboprobes that had been labelled internally with ${ }^{35}$ S-UTP $(800 \mathrm{Ci} / \mathrm{mmol}$; Amersham, UK). Synthesis of probes was carried out as described previously. ${ }^{21}$ Methods for pretreatment, hybridisation, washing, and dipping of slides in Ilford $\mathrm{K} 5$ for autoradiography were as described in detail previously. ${ }^{22}$ Autoradiography for TFF mRNA was at $4^{\circ} \mathrm{C}$ (two exposures per section 4 and $9 \mathrm{~d}$; $4 \mathrm{~d}$ for $\beta$-actin mRNA), before developing in Kodak D19 and counterstaining by Giemsa's method. Sections were examined under conventional or reflected light-dark field conditions (Olympus BH2 with epi-illumination) that allowed individual autoradiographic silver grains to be seen as bright objects on a dark background.

As a control to demonstrate the presence of hybridisable mRNA in specific compartments of the tissues studied, near serial sections were hybridised to an antisense $\beta$-actin probe. ${ }^{23}$

STATISTICAL ANALYSIS

Statistical analysis was performed using the $\chi^{2}$ test to assess the association of UACL with pouchitis, implying that UACL is a binary measure (yes/no). The difference was considered significant at a value of less than 0.05.

\section{Results}

MORPHOLOGY

All biopsy specimens obtained from pouches with pouchitis showed moderate to severe degrees of polymorphonuclear neutrophil infiltration and mucosal ulceration. Chronic inflammation and loss of villous height were also observed in all specimens of this group. Colonic phenotypic changes were detected in $50 \%$ of samples in this group, and no evidence of dysplasia was found. Biopsies from ileal reservoirs without pouchitis showed chronic inflammatory infiltrate and, in one case, mild polymorphonuclear infiltration. Biopsies from normal terminal ileum showed no acute or chronic inflammation.

New glands with the morphology of the UACL were observed in sections of six ileal reservoirs with pouchitis; on haematoxylin and eosin staining, these were lined by clear to pale staining cuboidal to low columnar epithelium and did not contain goblet cells in their fully formed state (fig 1A). The glands were in several cases small and incompletely formed. These buds contained neutral mucin and stained positively and pink with periodic acidSchiff, in contradistinction to the strong alcianophilic staining of the goblet cells in the parent epithelium which contains mainly acid mucin (fig 1B). None of the biopsies from ileal pouches without pouchitis and normal terminal ileum showed UACL glands $(p<0.05)$.

LOCALISATION OF TFF MRNA AND PROTEIN All samples showing UACL glands expressed TFF1 and TFF2 genes. TFF1 was expressed 

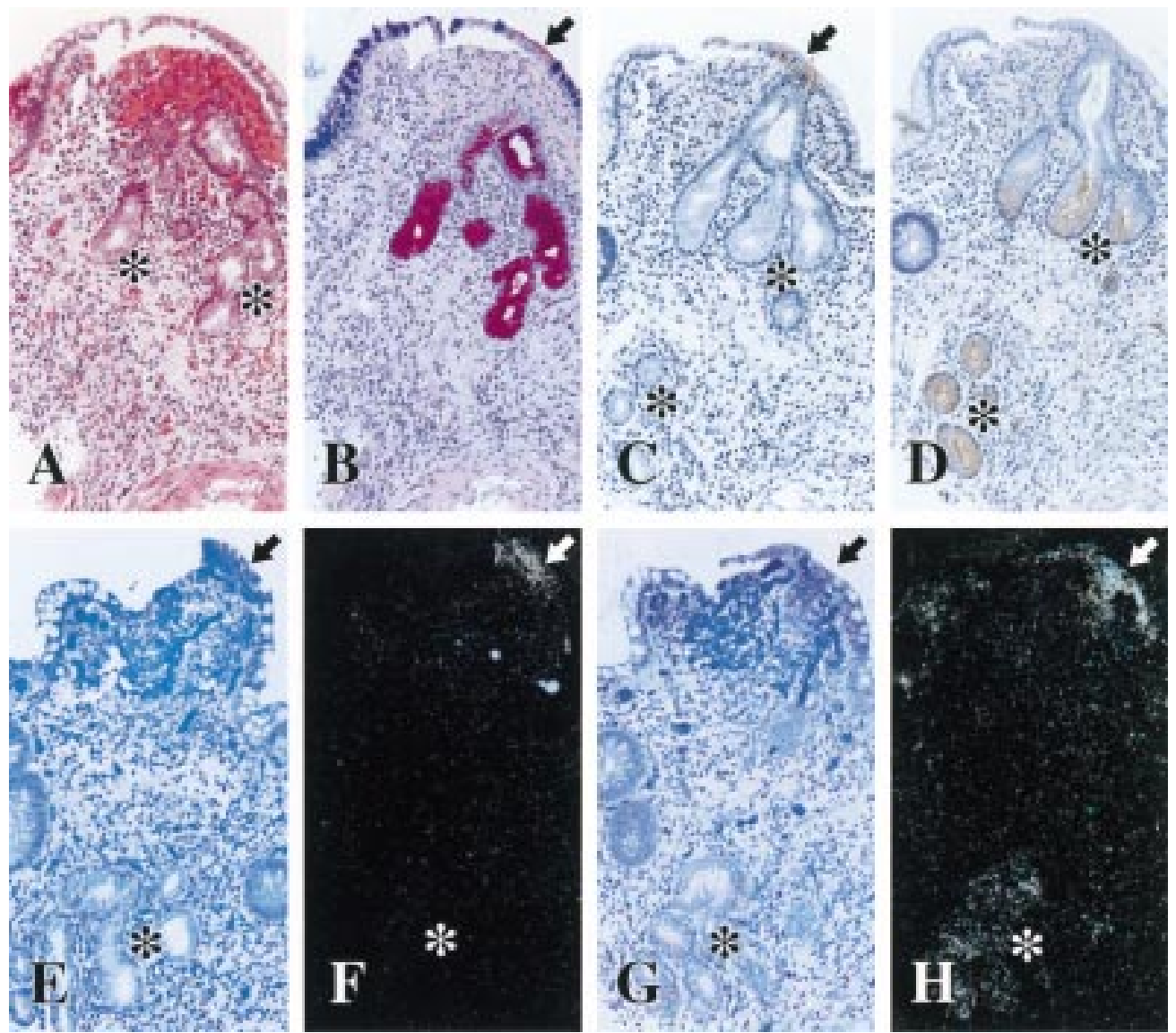

Figure 1 Histological sections of ileal pouch mucosa stained with: (A) haematoxylin and eosin showing some inflammation and profiles of ulcer associated cell lineage (UACL) glands (asterisks); (B) diastase periodic acid-Schifflalcian blue showing magenta neutral mucin UACL acinar and surface cell (arrow) compartments and alcian blue positive goblet cells; (C) trefoil factor family (TFF) 1 monoclonal antibody showing the presence of this peptide in UACL surface cells; (D) TFF2 monoclonal antibody showing the presence of this peptide in lower duct and acinar cells; (E, $F$ ) antisense TFF1 riboprobe showing the presence of TFF1 $\mathrm{mRNA}$ in UACL surface cells (arrow) but not acinar regions (asterisk) or goblet cells; $(G, H)$ antisense TFF3 riboprobe showing the presence of TFF3 mRNA in both surface (arrow) and acinar (asterisk) regions of the UACL gland as well as in some goblet cells.

in the distal ducts and surface cells of the UACL (fig 1C, E, F), and the buds, acini, and proximal ducts contained abundant TFF2 mRNA and immunoreactive peptide (fig 1D). This pattern of distribution is the same as described previously in this cell lineage. However, in some but not all UACL glands there was also TFF3 mRNA (fig $1 \mathrm{G}, \mathrm{H}$ ). The strength of the hybridisation signal varied greatly depending on the segment of the acini. In addition, TFF 1 and TFF 3 were detected in the monolayers of epithelial cells extending over the ulcerated mucosa. Paneth cells in intestinal crypts did not show detectable TFF3 mRNA.

Neither TFF1 nor TFF2 were detected in biopsies from ileal pouches without pouchitis or normal terminal ileum. TFF3 mRNA was detected in goblet cells in the three groups but no attempts were made to compare levels of expression quantitatively.

\section{Discussion}

The results of the present descriptive study add new information to knowledge of the morphological changes that the ileal pouch mucosa undergoes in patients with pouchitis, and provide further evidence for the role of the UACL as a repair system in the gastrointestinal tract.
Microscopic examination of pouchitis biopsies shows chronic inflammatory infiltration, abundant polymorphonuclear cells, goblet cell depletion, crypt abscesses, and mucosal ulceration. ${ }^{4}$ Our findings indicate that the presence of the UACL is also a common histological feature in the mucosa of pouches affected with this frequent long term complication. The UACL is a complex glandular structure containing neutral mucin secreting cells and is localised in the lamina propia close to the ulcer margins. ${ }^{14}$ This new cell lineage synthesises and secretes EGF, TGF- $\alpha$, and TFF peptides. As all of these peptides are known to participate in repair processes in the gut, it has been suggested that the UACL belongs to the group of so-called "reparative lineages" including Brunner's and pyloric glands. ${ }^{24}$ Although most frequently seen in the small intestine, particularly in Crohn's disease, the UACL also appears in the colon, although by no means as commonly. ${ }^{14}$ The frequent development of UACL glands in pouchitis shows that this mechanism for promoting repair is available even when the mucosa has begun to adapt to the colonic phenotype.

It has been proposed that the UACL forms by extrusion from the base of an intestinal 
crypt adjacent to the ulcer, followed by formation of an acinar structure, and an elongated duct that extends towards the surface. ${ }^{14}$ Thus chronic mucosal ulceration appears to be the signal for the development of the UACL. It is interesting to note that we did not find UACL glands in healthy pouches. The absence of this distinct cell lineage in biopsies from ileal reservoirs without pouchitis indicates that chronic inflammation is not enough to induce the growth of the UACL, and supports the hypothesis of intestinal ulceration as the stimulus for its development. Duration of inflammation and ulceration necessary to induce the UACL is not known. An animal model for the study of the UACL has recently been described and should help solve some of the questions regarding this cell lineage. ${ }^{25}$

The trefoil peptides are secreted by specific regions of the human gastrointestinal mucosa: TFF 1 by the stomach, TFF 2 by the stomach and duodenum, and TFF3 by goblet cells of small and large intestine. ${ }^{26}$ There is increasing evidence that these peptides play a role in the maintenance and gut healing process. These molecules are expressed in large amounts in chronic inflammatory bowel disease $\mathrm{e}^{27}$ and around peptic ulcers, and are upregulated rapidly after experimental gastric damage. ${ }^{28}$ Transgenic mice that have had the TFF3 gene knocked out have an increased susceptibility to gastrointestinal damage. ${ }^{29}$ These mice develop severe ulceration and haemorrhage after infusion of small amounts of mild irritants into the colon. Some studies indicate that TFF peptides interact directly with mucin glycoproteins promoting a rise in the viscosity of the protective overlying mucous gel. ${ }^{30}$ In addition, all three trefoil peptides are motogens ${ }^{17}$ and improve wound healing after injury. ${ }^{28}{ }^{31}$ Ectopic expression of TFF1, TFF2, as well as continued expression of TFF3 in areas of ulceration may be important because all are effective in restitution. Moreover, the UACL is a rich source of EGF and TGF- $\alpha$, and so is providing locally mitogens as well as motogens. Synergy between EGF and TFF3 systems has been described. In vitro, TFF3 enhances the epithelial ion transport in response to $\mathrm{EGF}^{32}$ and, in vivo, potentiates the wound healing activity of EGF without increasing its proliferative action. $^{33}$

TFF peptides show distinct patterns of expression in the gastrointestinal tract. In the UACL, TFF1 localises in the surface cells and distal duct, and TFF 2 is expressed in the acinar portion, ${ }^{11}$ as we found in biopsies from patients with pouchitis. Interestingly, we have also detected TFF3 mRNA in surface cells and acini of some UACL glands, as has been reported only for the UACL in Crohn's disease. ${ }^{34}$ It has been suggested that synthesis and secretion of trefoil peptides is always accompanied by secretion of a specific type of mucin. ${ }^{26}$ Thus there would be an association of expression of TFF1 and TFF2 with neutral mucins, and TFF3 would always be coexpressed with acid mucin with an affinity for alcian blue. However, the finding of TFF3 mRNA in neutral mucin secreting cells located at the UACL acini does not support this hypothesis.

TFF1 peptide is not only secreted locally into the mucosal surface by UACL cells but also in an endocrine or paracrine manner by neuroendocrine cells adjacent to the UACL to produce manifold effects in the gut. ${ }^{27}$ Normal serum levels of TFF1 are increased in patients with active Crohn's disease. ${ }^{35}$ Thus it is worth considering the possibility that the severity of pouchitis could be measured, or even flare ups predicted, by measuring levels of TFF peptides. $^{36}$

In summary, UACL glands arise de novo in the ileal pouch mucosa affected with pouchitis and express all three TFF peptide genes. This finding supports the role of this new cell lineage as a repair system within the gut. The results of this study suggest that mucosal ulceration is involved in the histogenesis of the UACL.

This work was supported by Mayo Foundation Rochester, MN, and the Imperial Cancer Research Foundation, London, UK, We are grateful to Rosemary Jeffery and Jan Longcroft for skilled We are grateful to Rosemary Jeffery and Jan Longcr
assistance with the in situ hybridisation studies.

1 Pemberton JH, Kelly KA, Beart RW, et al. Ileal pouch-anal anastomosis for chronic ulcerative colitis. Ann Surg 1987;206:504-13

2 Moskowitz RL, Shepherd NA, Nicholls RJ. An assessment of inflammation in the reservoir after restorative proctoof inflammation in the reservoir after restorative proctocolectomy 1 : $167-74$.

3 Shepherd NA, Jass R, Duval Y. Restorative proctocolectomy with ileal reservoir: pathological and histochemical study of mucosal biopsy specimens. F Clin Pathol 1987;40:601-7.

4 de Silva HJ, Millard PR, Kettlewell M. Mucosal characteristics of pelvic ileal pouches. Gut 1991;32:61-5.

5 Setti Carraro P, Talbot IC, Nicholls RJ. Long term appraisal of the histological appearances of the ileal reservoir mucosa after restorative proctocolectomy for ulcerative colitis. Gut 1994;35:1721-7

6 Sandborn WJ. Pouchitis following ileal pouch-anal anastomosis: definition, pathogenesis, and treatment. Gastroenterology 1994;107:1856-60.

7 Heppell J, Kelly KA. Pouchitis. Curr Opin Gastroenterol 1998;14:2-8

8 Thompson-Fawcet MW, Jewell DP, Mortensen JM. Ileoanal reservoir dysfunction: a problem-solving approach. $\mathrm{Br} F$ reservoir dysfunction:

9 de Silva HJ, Millard PR, Soper N, et al. Effects of the faecal stream and stasis on the ileal pouch mucosa. Gut 1991;32: stream and

10 Hanby AM, Wright NA. The ulcer-associated cell lineage: the gastrointestinal repair kit? F Pathol 1993;171:3-4.

11 Liber AF. Aberrant pyloric glands in regional ileitis. Arch Pathol 1951;51:205-12.

12 Hanby A, Jankowski J, Elia G, et al. Expression of the trefoil peptides pS2 and human spasmolytic polypeptide (hSP) in Barrett's metaplasia and the native esophageal epithelium: delineation of a epithelial phenotype. $\mathcal{F}$ Pathol 1994;173: 213-19.

13 Wright N, Poulsom R, Stamp G. Epidermal growth factor (EGF/URO) induces expression of regulatory peptides in damaged gastrointestinal tissues. F Pathol 1990;162:27984.

14 Wright NA, Pike C, Elia G. Induction of a novel epidermal growth factor secreting lineage by mucosal ulceration in growth factor secreting lineage by mucosal ulceration in
human gastrointestinal stem cells. Nature 1990;343:82-5.

15 Wright N, Hoffman W, Otto W, et al. Rolling in the clovertrefoil factor (TFF) domain peptides, cell-migration and trefoil factor (TFF) domain peptides,
cancers. FEBS Letters 1997;408:121-3.

16 Dignass A, Lynch-Devaney K, Kindon H, et al. Trefoil peptides promote epithelial migration through a transforming growth factor- $\beta$ independent pathway. $\mathcal{F}$ Clin Invest 1994; 94:376-83.

17 Thim L. Trefoil peptides: from structure to function. Cell Mol Life Sci 1997;53:888-903.

8 Penna C, Dozois R, Tremaine W, et al. Pouchitis after ileal pouch-anal anastomosis for ulcerative colitis occurs with increased frequency in patients with associated primary sclerosing cholangitis. Gut 1996;38:234-9.

19 Sandborn WJ, Tremaine WJ, Batts KP. Pouchitis after ileal pouch-anal anastomosis: A pouchitis activity index. Mayo Clin Proc 1994;69:409-15.

20 Hanby AM, Poulsom R, Singh S, et al. Spasmolytic polypeptide is a major antral peptide: distribution of the polypeptide is a major antral peptide: distribution of the
trefoil peptides human spasmolytic polypeptide and pS2 in trefoil peptides human spasmolytic polypeptide and
the stomach. Gastroenterology 1993;105:1110-16.

21 Poulsom R, Hanby AM, Lalani EN, et al. Intestinal trefoil factor (TFF3) and pS2 (TFF1), but not spasmolytic polypeptide (TFF2) mRNAs are co-expressed in normal 
hyperplastic and neoplastic human breast epithelium. $\mathcal{F}$ Pathol 1997;183:30-8.

22 Poulsom R, Longcroft JM, Jeffery RE, et al. A robust method for isotopic riboprobe in situ hybridisation to localise mRNAs in routine pathology specimens. Eur $\mathcal{f}$ Histochem 1998, $2: 12$

23 Zandvliet DWJ, Hanby AM, Austin CA, et al. Analysis of foetal expression sites of human type II DNA topoisomerase $\alpha$ and $\beta$ mRNAs by in situ hybridisation. Biochim Biophys Acta 1996;1307:239-47.

24 Ahnen D, Poulsom R, Stamp G. The ulceration-associated cell lineage (UACL) reiterates the Brunner's gland differentation programme but acquires the proliferative organization of the gastric gland. F Pathol 1994;173:31726.

25 Hanby AM, Pera M, Filipe I, et al. Duodenal content reflux esophagitis in the rat: An animal model for the ulcerassociated cell lineage (UACL)? Am f Pathol 1997;151: associated

26 Poulsom R. Trefoil peptides. Baillieres Clin Gastroenterol Cytokines Growth Factors Gastroenterol 1996;10:113-34.

27 Wright NA, Poulsom R, Stamp G, et al. Trefoil peptide gene expression in gastrointestinal epithelial cells in inflamma-

28 Playford RJ, Marchbank T, Chinery R, et al. Human spasmolytic polypeptide is a cytoprotective agent that stimulates cell migration. Gastroenterology 1995;108:10816.
29 Mashimo H, Wu DC, Podolsky D, et al. Impaired defense of intestinal mucosa in mice lacking intestinal trefoil factor. intestinal mucosa in mice
Science 1996;274:262-5.

30 Kindon H, Pothoulakis C, Thim L, et al. Trefoil peptide protection of intestinal epithelial barrier function: cooperative interaction with mucin glycoprotein. Gastroenterology 1995;109:516-23.

31 Babyatsky M, DeBeaumont M, Thim L, et al. Oral trefoil peptides protect against ethanol- and indomethacininduced gastric injury in rats. Gastroenterology 1996;110: 489-97.

32 Chinery R, Cox HM. Modulation of epidermal growth factor effects on epithelial ion transport by intestinal trefoil factor. Br f Pharmacol 1995;115:77-80.

33 Chinery R, Playford R. Combined intestinal trefoil factor and epidermal growth factor is prophylactic against indomethacin-induced gastric damage in the rat. Clin $\mathrm{Sci}_{\mathrm{i}}$ 1995;88:401-3.

34 Hauser F, Poulsom R, Chinery R, et al hP1.B, a human $\mathrm{P}$-domain peptide homologous with rat intestinal trefoil factor, is expressed also in the ulcer-associated cell lineage and the uterus. Proc Natl Acad Sci USA 1993;90:6961-5.

35 Duclos B, Rio M-C, Reimund JM, Chamouard P, et al. Increased $\mathrm{pS} 2$ secretion in serum of Crohn's disease patients. Gastroenterology 1996;100:A520.

36 Miyashita S, Nomoto H, Konishi H, et al. Estimation of pS2 protein level in human body fluids by a sensitive two-site enzyme immunoassay. Clin Chim Acta 1994;228:71-81.

\title{
Narrative Based Medicine, An Interdisciplinary Conference
}

\author{
Research, Narrative, and Practice
}

A two day conference-Monday 3rd and Tuesday 4th September 2001

Homerton College, Cambridge, UK

BMF Publishing Group

For full details contact: BMA/BMJ Conference Unit, Tavistock Square, London, WC1H 9JP Tel: +44 (0)20 7383 6819; fax: +44 (0)20 7383 6663; email: clyders@bma.org.uk. www.quality.bmjpg.com 